Schulich School of Law, Dalhousie University

Schulich Law Scholars

2013

The Role of EA in Achieving a Sustainable Energy Future in Canada: A Case Study of the Lower Churchill Panel Review

Meinhard Doelle

Follow this and additional works at: https://digitalcommons.schulichlaw.dal.ca/scholarly_works

Part of the Environmental Law Commons 


\section{The Role of EA in Achieving a Sustainable Energy Future in Canada: A Case Study of the Lower Churchill Panel Review.}

Meinhard Doelle

JELP Conference

May 2012

\section{Introduction}

Energy projects have featured prominently in environmental assessment (EA) processes in Canada, particularly with respect to panel reviews conducted under the Canadian Environmental Assessment Act (CEAA). ${ }^{1}$ Examples include offshore oil \& gas, tar sands developments, pipeline projects, nuclear energy projects, liquefied natural gas (LNG) facilities, and large-scale hydro projects. ${ }^{2}$ Over the past three decades, since the failed attempt at a national energy policy in the 1970s, these panel reviews have served as an important forum for public debate on broader energy policy issues.

There are, of course, limits to the ability of project EAs to address such broader energy policy issues. ${ }^{3}$ However, there are provisions in CEAA that encourage the consideration of broader issues beyond individual projects, most notably the consideration of the need and purpose of a project, alternatives to a project, and cumulative effects. ${ }^{4}$ The ultimate test of whether significant adverse effects are justified in the circumstances under CEAA provides a further avenue for considering such issues. ${ }^{5}$ In spite of these efforts under CEAA, experience over time has shown that the constraints on project EAs to consider broader policy issues can be considerable.

This article assesses a recent panel review of the Lower Churchill (LC) hydroelectric project in Labrador to consider the role of project based EA in achieving a sustainable energy future for Canada. ${ }^{6}$ The aim of the article is to separate inherent limitations of project based EA from challenges that can be overcome through adjustments to the current panel review process. $^{7}$

The article starts with a general overview of the LC project and the joint panel review process designed by the federal government and the government of Newfoundland and Labrador. This is followed by reflections on the how the process used affected the ability to consider the possible contribution of the LC project to a sustainable energy future for Canada. In the final section, the article looks more closely at two particularly relevant aspects of the process, the consideration of alternatives to the project, and the Panel's proposed approach to assessing the project's net contribution to sustainability.

\section{Overview of The LC Panel Review}


The Lower Churchill Joint Review Panel Process involved a proposed hydroelectric project in Central Labrador. The project proponent is Nalcor Energy, a provincial crown corporation responsible for a range of energy enterprises in the province. The project includes two proposed hydroelectric dams on the Churchill river, one at Gull Island, about $230 \mathrm{~km}$ downstream of the current facility at Churchill Falls, and the other at Muskrat Falls, about $60 \mathrm{~km}$ further downstream, and about $30 \mathrm{~km}$ upstream of Happy Valley Goose Bay. The proposed Gull Island facility is about 100 meters high and would have a maximum capacity of over 2000 MW. The Muskrat Falls facility would be about 30 meters tall and have a capacity of 800 MW. ${ }^{8}$

Also included in the project for purposes of the environmental assessment by the Joint Review Panel was an interconnecting transmission line that connects both facilities with each other and with the existing grid in Labrador. Not included in the project were new transmission lines needed to take the power to be generated to markets. ${ }^{9}$ Additional transmission would be required to reach markets in coastal areas of Labrador, on the island of Newfoundland, Eastern Canada and New England. A proposed transmission link to the island of Newfoundland is the subject of a separate environmental assessment. ${ }^{10} \mathrm{~A}$ third assessment is being carried out for the transmission link to Nova Scotia. ${ }^{11}$

The Panel's mandate was not unlike other JRP's in that the Panel was asked to consider the various factors set out in Section 16 of CEAA. At the heart of the mandate was the consideration of biophysical, social, economic, and cultural effects of the project and their significance, and the consideration of mitigation measures to reduce or eliminate any impacts identified. Also included in the mandate were the need, purpose, rationale for the project, alternatives and alternative means of carrying out the project, accidents and malfunctions, cumulative effects, and monitoring and follow-up. The panel was also asked to consider benefits of the project and ways to enhance those benefits. ${ }^{12}$

The mandate of the LC panel differs from some other CEAA panels in that the panel was not asked to draft the EIS guidelines or otherwise engage in a scoping process. Scoping hearings had been the norm for panel reviews, but this practice has recently been discontinued. In another departure from past practice, the terms of reference do not specifically ask the panel for an overall recommendation as to whether the project should proceed or not.

With respect to aboriginal issues, the panel was asked to report on current use for traditional purposes by aboriginal peoples, and on any information provided by aboriginal communities on claims to aboriginal rights and title. The Panel was specifically asked not to comment on the strength of such claims or on the adequacy of any consultations with aboriginal communities by or on behalf of the federal or provincial crown. ${ }^{13}$

The process followed by the LC JRP was otherwise quite standard for panel reviews carried out in Canada since the entry into force of CEAA in 1995. The process was 
initiated with the release of the memorandum of understanding, the panel's terms of reference, and the EIS guidelines in the fall of 2008. The appointment of the joint review panel followed in January, 2009. The proponent released its EIS in February, 2009 , followed by a public comment period on its adequacy. ${ }^{14}$

Based on its own review of the EIS and comments filed by government departments and intervenors, the panel determined that it required additional information from the proponent before it could proceed to hearings. The panel submitted over 100 information requests to the proponent in the spring of 2009. The proponent responded in the fall. Following a public comment period on the proponent's responses and a review of the information by the panel, another set of information requests were filed in January, 2010. The proponent responded to this set of information requests in the fall of $2010 .^{15}$

A final round of information requests was submitted in late fall of 2010 in part due to a change to the project by the proponent. Initially, the project was proposed to commence with the construction of the Gull Island Facility, followed by the Muskrat Falls facility. The proponent advised the panel in late 2010 that it now anticipated commencing with Muskrat Falls first, largely because it had entered into an agreement with Emera of Nova Scotia for the transmission of excess power from Muskrat falls to markets in NS and beyond. Responses to the last round of information requests were filed by January, 2011.16

In January, 2011, the panel determined that it had sufficient information from the proponent to proceed to the hearings. This determination was based on the panel's review of the information provided by the proponent in light of the EIS guidelines issued by the Minister and the comments and questions submitted by government departments and intervenors. The hearings took place between March 2 and April 15, 2011. Most of the hearings took place in Happy Valley Goose Bay, however, the panel also traveled to St John's, Sept Iles, Mud Lake, Northwest River and Sheshatshiu. In addition, the panel conducted a number of sessions by videoconference to coastal communities in Labrador. The panel's final report was released on August 23, 2011. ${ }^{17}$ The federal and provincial governments released their formal responses to the panel report on March 15, 2012.18

The process involved a relatively limited number of active participants, though strong for the population size of affected communities. Aboriginal representation was strongest from the Inuit of Labrador, represented by the Nunatsiavut Government, and by the Innu Nation of Labrador. The participation of the Labrador Metis association, Nunatukavut, was more limited. Its involvement in the hearings, in particular, was limited due to a court challenge it initiated at the start of the hearings. By the time the application for an interim injunction to stop the hearings was denied, there was limited opportunity for engagement in the process. Seven aboriginal communities in Quebec participated in some form in the process, most by presenting to the panel during the community hearings in Sept Isle. ${ }^{19}$ 
The involvement of aboriginal peoples in the LC panel review process was complex for a number of reasons, including a number of overlapping claims, divergent interests, and the introduction of a consultation framework part way through the EA process. ${ }^{20}$ On the Labrador side, the process involved three organizations at very different stages of settling their claims to rights and title. The Inuit had settled their land claim and engaged through the Nunatsiavut government established as part of the settlement. The Innu Nation had recently signed an agreement in principle to settle their land claim and to provide for redress for impacts from the existing hydro project at Churchill Falls. It had also signed an impacts and benefits agreement for the Lower Churchill project. ${ }^{21}$

The Labrador Metis, now operating through an association named Nunatukavut, has had its aboriginal rights claim accepted for negotiation federally but not provincially. Seven aboriginal communities physically located in Quebec claim rights and title to land and resources potentially affected by the project. Some of these communities have claims that overlap with those of aboriginal groups in Labrador. The proponent initiated negotiations for a community consultation agreement with each of the potentially affected communities, but only reached a successful outcome with the Innu Nation of Labrador and an initial consultation agreement with one of the aboriginal communities in Quebec. ${ }^{22}$

Other intervenors included the Sierra Club, the Grand River Keepers, local and provincial economic development associations and members of the public. Hydro Quebec commented on the adequacy of the EIS, but otherwise did not participate in the EA process. Many of the non-governmental intervenors were either generally opposed to the project or expressed concerns with specific aspects. A number of aboriginal communities expressed opposition to the project as proposed, particularly the Nunatsiavut Government and Nunatukavut. A number of Quebec communities also expressed concerns about the project. The leadership of the Innu Nation appeared generally supportive of the project, but it also expressed concerns with specific aspects of the proposal. Individual members of aboriginal communities, particularly elders, did not always share the views of the leadership. The strongest opposition to the project came from the Grand River Keepers and the Atlantic Chapter of the Sierra Club. Some, such as economic development associations, were generally supportive of the project. Most government departments focused on providing technical advice on areas within their mandate. Some provincial departments spoke in favour of the project, while federal representatives generally did not comment on the overall project. ${ }^{23}$

Views expressed about the project ranged from concerns about the biophysical impacts of the impoundment to the manner in which the project was proposed and how the costs and benefits were to be distributed. Many intervenors questioned the rationale for the project, and suggested that there were better ways to meet the stated objectives of energy security, energy price stability, reduced GHG emissions from electricity, and long-term revenues to the province. Other participants were more supportive of the project, seeing it as an important economic driver for the 
region and an opportunity for aboriginal communities, particularly the Innu Nation, to make the transition to a wage economy and develop the financial resources to take control of their own destiny. ${ }^{24}$

The panel did not reach an overall conclusion on whether the project should proceed. It did, however, identify a number of significant adverse environmental effects, mostly related to the biophysical impacts associated with the impoundment of the river. It also identified a number of potential benefits, such as social and economic benefits to the area, and benefits associated with a long-term source of low GHG energy. The panel furthermore concluded that it was not provided with sufficient information to conclude whether the project was justified from an economic perspective and whether there were alternatives that were preferable to the project. ${ }^{25}$ The implications of the project on aboriginal rights, title and on current use for traditional purposes could also not be fully assessed by the Panel, making an overall conclusion on the project impossible.

In place of an overall conclusion, the panel offered government decision-makers an approach to reaching an overall decision on the project based on whether the project would make a net contribution to sustainability. In this regard, the panel essentially suggested that in order for a project to make a net contribution to sustainability, it should strive to provide net environmental, net social and net economic benefits. Furthermore, the benefits, impacts, risks and uncertainties should be distributed fairly both geographically and between current and future generations. Chapter 17 of the panel report offers a more detailed analysis of how a decision on the projects contribution to sustainability might be made, and how such an approach might affect whether and under what conditions the project might be approved. ${ }^{26}$

\section{Reflections on the LC Panel Review Process}

With an eye to the goal of assessing the role of project EA in ensuring a sustainable energy future, this article considers both the process and substance of the LC panel review. The process is considered first to determine whether it is designed to make effective use of the opportunity to shape our energy future at the project level. With this in mind, the following are reflections on the JRP process based on the author's experience as a panel member on the Lower Churchill Panel.

As briefly mentioned above, the early practice for CEAA panels had been to involve the panel in the scoping process. Until recently, the practice had been for the Ministers to set the broad scope parameters, but to give the Panel the mandate to schedule scoping hearings and to develop the EIS guidelines. ${ }^{27}$ This allowed for more public input into the scoping process and it allowed the Panel to take ownership of the scope of the assessment and the direction to the proponent in the form of the EIS guidelines. 
The LC Panel review process is part of a recent trend away from this practice. The LC panel was not involved in developing the EIS guidelines, and it was not mandated to hold scoping hearings. This left numerous uncertainties in the eyes of participants on how the EIS guidelines related to the term of reference, and how the two combined to determine the scope of the assessment. ${ }^{28}$ In the end, the Panel accepted the Terms of Reference as the final word on the scope, and the EIS Guideline as direction to the proponent on what to include in the EIS rather than as a scoping document for the overall process. This meant, however, that there were issues within the scope of the EA on which the proponent was not required by the EIS guidelines to provide information. ${ }^{29}$

Another troubling trend is the shift from a Valued Environmental Components (VEC) approach to the assessment of environmental effects of the project to an approach based on key indicator species. This trend is troubling in at least two respects. First, there has been a tendency with the key indicator approach to limit the assessment to the selected indicator species, and eliminate the essential second step to then consider what the effects of the project on the selected indicator species tells us about the broader effect of the project on all VECs. Furthermore, a key indicator species approach increases the risk that ecosystem health and resilience is undervalued in the assessment. ${ }^{30}$

Another observation on the panel review process as currently practiced is the role of intervenors. The primary role of intervenors in the LC panel review process from February 2009 to January 2011 was to review information provided by the proponent in the form of the EIS and responses to the Panel's information requests. Only then, after the Panel determined that it had sufficient information from the proponent to proceed to hearings, were intervenors invited to submit their own evidence and their own views on the project.

The intervenors were therefore engaged in the process for two years before the Panel had the benefit of their detailed views and evidence about the effects of the project. This hampered the Panel's ability to critically assess the proponent's submissions, and it puts intervenors at a disadvantage in terms of shaping the views of the Panel about the project.

While it is understandable that the proponent would have the primary responsibility to provide information to the panel about the projects potential interactions with the receiving environment, it would enhance the process to invite intervenors to submit their own views and their own evidence at any time following the submission of the proponent's EIS. Such an adjustment to the process has the potential to allow the Panel to identify key areas of disagreement much earlier, and as a result expedite the information request process, and allow the hearings to focus on key areas of disagreement.

There has been considerable discussion recently about the length of some panel reviews. It is important to note, in this regard, that most of the time in the LC panel 
review was taken up with the process of requesting information from the proponent to ensure compliance with the EIS guidelines and to ensure enough information was available on key issues to be able to proceed to the hearings. This part of the EA process took about two years, the rest of the panel review process took less than six months. The panel had 45 days to conduct its hearings and 90 days to write its report. ${ }^{31}$ If there are efficiencies to be gained in panel review processes, they have to involve ways to get better quality information from proponents at the start of the process.

Scoping hearings that engage all interested parties can be an effective way to communicate to proponents the type of information and the level of detail required. In the case of the LC process, discussions at the hearings on issues such as alternatives and current use for aboriginal purposes seemed to, for the first time, give the proponent a full appreciation of the information needed. Unfortunately, there was insufficient time at this late stage of the process to gather the information. As a result, in spite of two years of back and forth, the Panel was left with critical information gaps on key issues such as alternatives to the project and the impact of the project on current use by aboriginal peoples, particularly with respect to the Metis in Labrador and aboriginal groups in Quebec.

An interesting related issue was the Panel's sufficiency determination..$^{32}$ This determination has important implications for the length of the panel review process and for the ultimate outcome. In the LC review process, the panel essentially took the view that the minimum standard was that the proponent had provided basic information and explained its position on each of the issues in the EIS guidelines. The panel did not hold up its sufficiency finding just because it would have liked more detailed information or justification of the positions taken. To do so might have prolonged the information request stage of the process much longer than the two years it took. The implication of this was that on some issues, such as current use for traditional purposes and alternatives to the project, the panel never did receive the level of detail it desired before the hearings.

It is important to note that the sufficiency determination was based on compliance with the EIS Guidelines, not based on the scope of the Panel's terms of reference. Many of the issues on which the panel was seeking additional information, including alternatives, were defined more narrowly in the EIS guidelines than the Panel's terms of reference. The Panel took the view that it was not in a position to hold up its sufficiency determination until the proponent had provided information, if the information requested went beyond the requirements of the EIS Guidelines.

The Panel decided to deal with the issue of not receiving all the information it had requested by trying to be very clear with the proponent on the information it desired, and to clearly communicate that it intended to apply a precautionary approach to information gaps, including those resulting from unsatisfactory responses to information requests. At the same time, the panel decided not to hold up the hearings until all the requested information had been provided. 
This approach, of not persisting to ask for information not required under the EIS Guidelines but important under the Terms of Reference, was taken in part on the basis that the positions of the proponent was clear, and that the unresolved issued could be addressed at the hearings, including possible further undertakings if needed. The Panel also committed to applying precaution in dealing with information gaps in writing its final report. In the end, this approach proved challenging to implement. With respect to alternatives, in particular, the Panel was left in the unenviable position of having to recommend an independent alternatives assessment, something the panel would have preferred to be able to complete as part of the panel review process. ${ }^{33}$

A related challenge in the LC panel review process is the need to bring credible expertise on complex technical issues before the panel. Under the current approach, this is essentially left to the proponent, government departments and intervenors. Under this model, it is left to the panel to determine the credibility, accuracy and relevance of the information provided. In order for the panel to be able assess the information provided on behalf of the proponent, others involved in the process have to have the resources and motivation to challenge the information provided by the proponent, offer opposing views, and fill information gaps.

Government departments sometimes fill this role effectively, but there are also instances where governments either lack the credibility because they have taken a public position on the project, or they lack the resources or technical expertise to contribute effectively to the EA process. Intervenors can play this role, but they are generally under-funded, making it impossible to do so effectively. In the LC panel review, only the Innu Nation and Hydro Quebec appeared to have significant resources at their disposal to challenge the technical information put forward by the proponent. Others, such as the Grand River Keepers, made a considerable effort, but were clearly constrained by a lack of resources.

This can leave panels with one-sided information and a lot of questions. Panel secretariats do offer technical support, but such support can only raise questions, it cannot be the source of new information. Secretariat analysts cannot offer new information to panel members because the support provided by the secretariat is not open to public scrutiny. ${ }^{34}$ In theory, panels have the ability to subpoena witnesses and to hire their own experts. The subpoena power is rarely if every exercised, and in the authors experience does not appear to be a practical option for getting an independent impartial perspective on complex technical issues.

Based on all of this, access to independent experts would seem critical to the effective operation of the panel process. As long as the experts and the information they offer are accessible to the public in a timely manner, independent experts would make a valuable contribution to the EA process. Lack of resources, time constraints and procedural challenges prevented the LC Panel from utilizing independent experts on a range of issues such as alternatives, electricity markets, 
and the relationship between electricity grid infrastructure and the unique characteristics of different sources of electricity.

Government Departments could play an enhanced role in the panel review process. Currently, departments offer advice on issues they identify to be within their area of expertise or interest. Some are motivated by pending regulatory or funding decisions. Others have a mandate to address specific issues or to protect certain environmental components potentially affected by the project. A useful addition to the process might be a more formal allocation of areas of responsibility to federal and provincial departments based on jurisdiction, expertise and mandate. This could be done in a manner that ensures that each of the standard issues raised in most environmental assessment are clearly allocated to at least one government department. Each department could then be given a formal responsibility to carry out a peer review of the information provided by the proponent, rather than just be invited to comment on issues of interest or concern. ${ }^{35}$

The relationship between the Panel and the Ministers can also hinder the effectiveness of the process. The LC panel dealt with a number of different federal and provincial Ministers. A consistent experience was that it took considerable time to hear back from Ministers, particularly at the federal level. This meant that issues that arose could not be resolved quickly. An example would be a request by the Panel to amend the terms of reference to address a problem with the requirement to translate documents. ${ }^{36}$ Unless issues were identified early, the Panel was essentially on its own and required to work within the existing framework as provided by the terms of reference, even where it created unexpected difficulties for the process. Efficiencies in the process could be improved if there was an expedited procedure for getting responses from responsible Ministers on key issues.

It is important to keep these observations on possible improvements to the panel review process in perspective. Panel reviews are the highest level of EA in Canada with a proven track record of independence, of public engagement, and of improved project level decision-making. The value of the independence of the panel for the integrity of the process and for the assessment of the information is particularly noteworthy based on the experience with the LC panel review process.

It was clear, for example, that the close relationship between the proponent, Nalcor and the provincial government would have undermined the credibility of any EA process under the sole control of the provincial government. Federal departments, while very helpful in providing specific technical information on a range of issues, generally demonstrated a reluctance to consider issues beyond their individual mandates.

The relationship between a number of intervenors and both federal and provincial government departments had deteriorated by the time the hearings took place, making it difficult for government officials to take the substance of the submissions made by some intervenors seriously even when they had merit. The panel, which 
had no history of dealing with the participants in relation to the project, and no stake in the outcome, was in a much better position to impartially evaluate the substance of the issues various participants were putting forward and to evaluate their relevance to the EA process. It was clear from numerous comments made throughout the hearings that many participants valued the independence of the panel from government, and that it was this independence that had encouraged them to participate in the process ${ }^{37}$.

\section{The LC Panel Review and Sustainable Energy Policy: Seeing the Big Picture in Project EA}

Having considered possible adjustments to the EA panel process at the project level to enhance its effectiveness, in this section the substantive challenges faced in the LC panel review process in two key areas are discussed: alternatives to the project, and the project's net contribution to sustainability.

\section{Alternatives to the Project}

Having identified a number of significant adverse environmental effects of the project, the panel went on to consider whether there were alternatives to the project that could result in fewer significant adverse effects. The Panel's approach to the alternatives assessment and what it suggests for the role of project EAs in ensuring a sustainable energy future is reviewed in this section. The Panel considered the issue of alternatives to the project in three steps.

First, in order to be able to identify possible alternatives to the project, the need and purpose and rationale behind the project first had to be defined. As a second step the Panel considered whether there was either a single alternative or some combination of alternatives that could meet the need, purpose and rationale as defined. The third and ultimate question for the alternatives analysis would be whether any of the alternatives identified in step two could meet the need, purpose and rationale with a more desirable combination of effects, benefits, risks and uncertainties. ${ }^{38}$

With respect to the need, purpose and rationale, the proponent took the position that the Project was needed to address the future demand for electricity in Newfoundland and Labrador, and that its purpose and rational was to fully develop the province's hydroelectric resources in accordance with the provincial energy policy, to secure a renewable future, and generate long-term revenues for the Province. Based on this approach to need, purpose and rationale, the proponent concluded that there was no suitable alternative to the project.

Many intervenors rejected the proponent's approach to need, purpose and rationale, and suggested that the panel should consider only those objectives that demonstrably benefit the broader society. ${ }^{39}$ The objective of fully developing the hydro potential of the province without any connection to the benefits, impacts, 
risks and uncertainties associated with such development drew particular criticism from intervenors in this regard, as the acceptance of this objective would essentially undermine one of the key purpose of the LC panel review process by eliminating any meaningful consideration of alternatives.

The Panel concluded that of the objectives identified by the proponent, the critical issues from an alternatives perspective were the goals of meeting electricity needs in Newfoundland and of securing a renewable, low GHG emissions energy future for the region. The Panel concluded that the goal of securing long-term revenues to the province could be achieved through many other means if the resources allocated to this project were invested elsewhere, and that the goal of developing the full hydro potential of the province was not an appropriate goal for purposes of the alternatives assessment of the panel review process. ${ }^{40}$

As a result of its conclusion on need, purpose and rationale for the project, the panel proceeded to focus on demand management and various renewable energy sources as potential alternatives to the project. Furthermore, in light of the uncertainty over market access from Gull Island and given its conclusion that the stated objective of generating revenues for the province could be obtained through other forms of investments, the Panel decided to focus its alternatives assessment on the power to be generated from the Muskrat Falls facility. ${ }^{41}$

Of the $800 \mathrm{MW}$ of power expected, about $40 \%$ was reserved to meet immediate demand on the island of Newfoundland and replace an existing oil power plant, and $20 \%$ would be available to Nova Scotia as part of the agreement to construct a transmission link to Nova Scotia. The remaining $40 \%$ initially would be available for export to the Maritime Provinces and beyond, and for potential use in Labrador in case of significant industrial development. In the long term, some or all of this $40 \%$ was expected to be needed on the island of Newfoundland if demand continued to increase as predicted by the utility.

Unfortunately, the proponent had taken the position that part of the purpose was to develop the full hydro potential of the province, and that any alternative had to offer the full capacity of $3000 \mathrm{MW}$. Furthermore, the proponent was reluctant to rely on demand management due to limited experience with such efforts in the province. It was opposed to mandatory or financial measures to manage demand, and indicated that it was not in the business of encouraging fuel switching away from electric heat to better manage winter peak demand. Furthermore, Nalcor was reluctant to consider wind at a large scale on the island of Newfoundland because it would produce excess power in the summer months. As a result of these factors, the proponent never provided a detailed assessment of the potential of the combination of conservation, demand management and renewable energy production from wind and small-scale hydro to meet electricity demands on the island of Newfoundland. ${ }^{42}$

In response to various information requests and questions at the hearings, and in spite of its position on need, purpose and rationale, the proponent did provide some 
information on possible alternatives to meeting electricity needs on the island through demand management and renewable energy sources. The level of detail was, however, insufficient to allow for an independent assessment of their potential, particularly with respect to demand management and wind generation. The proponent concluded that none of the alternatives were price competitive, none could offer the same level of energy security, none would develop the remaining hydro-potential, and none would generate the same scale of revenues for the province. ${ }^{43}$

The Panel nevertheless considered which of the alternatives identified by the proponent and intervenors had the potential to service the island of Newfoundland market in a manner that had the potential to offer comparable energy security and emission reductions at a comparable cost. Energy conservation and other demand management efforts were at the top of the list. Next, the panel considered the role of wind, small-scale hydro and other sources of renewable energy to meet demand. Finally, the panel considered the option to utilize biomass, natural gas and oil to meet any remaining shortfall.

Intervenors offered some insights that suggested that some combination of demand management and wind power in particular had the potential to meet a significant portion of demand at competitive prices. However, the Panel never received sufficient technical and financial information to be able to determine whether these were viable alternatives to meeting island electricity demands into the foreseeable future. Similarly, very limited information was provided on alternatives to power from the project in export markets in the Maritime Provinces and beyond.

The absence of credible information on the impact of the addition of power from the project into the North American grid also created challenges. ${ }^{44}$ In the absence of a regional, national, or north American electricity or energy strategy, it was difficult for the Panel to reach any conclusions on the impact of the project on GHG emissions, on energy prices or on energy security beyond Newfoundland. ${ }^{45}$ This meant that claims about the benefits of proceeding with the project in terms of benefits beyond the province, while not unreasonable, could not be substantiated or quantified. Any alternatives assessment beyond alternative ways to meet demand in the province was therefore not seriously pursued.

In the end, the lack of independent technical expertise, and the absence of any process options at the end of the hearings prevented the Panel from completing its alternative assessment and left it to recommend an independent alternatives assessment be conducted before a final project decision is made. The EA process allowed the Panel to properly frame the parameters of the alternatives assessment, but it did not allow the Panel to complete the assessment itself. The improvements to the panel review process discussed in the previous section, such as better access to independent experts, an enhanced role for government departments in carrying out peer reviews of the information filed by proponents, engagement of the panel in the development of the EIS Guidelines, and re-introducing the scoping hearings as a 
forum to clearly articulate expectations on issues such as alternatives would go a long way toward addressing these challenges.

Another step forward in terms of alternative assessments in project EAs would be to assign the responsibility to offer technical information on possible alternatives to the proposed project to a specific government department or agency rather than the proponent. In the case of the LC panel review process, the proponent, Nalcor, had a mandate, as the provincial utility, to understand all the alternatives under considerations, so such an allocation of responsibility to government, while possibly helpful, should not have been necessary. However, in many cases the proponent has limited expertise on alternatives to its project. This, added to the lack of motivation for any proponent to fully consider alternatives to what they know and prefer, would make the allocation of responsibility for alternatives to a government department with expertise in the subject area a reasonable solution.

An effective alternatives assessment at the project EA level is critical if this process is to make a valuable contribution to ensuring a sustainable energy future. Project EAs simply cannot evaluate whether and how proposed energy projects may contribute to a sustainable energy future without a full consideration of the need, purpose, and rationale that is driving the project, and possible alternative ways of achieving the accepted goals. Ideally, such an alternative assessment will take place in the context of existing sustainable energy strategies in affected jurisdictions. Regardless of whether such higher tier strategies are in place, the contribution of the alternatives assessment at the project level can be enhanced through modest adjustments to the current process.

\section{Project Contribution to Sustainability}

As EAs have continued to move beyond the narrow focus on biophysical impacts of proposed new activities, the need for some framework to deal with the range of risks, costs and benefits of proposed projects has become more and more apparent. The terms of reference for the Lower Churchill panel review support this broader approach, in that they mandate the Panel to consider a broad range of social, cultural, economic and biophysical impacts of the Project. The Panel's approach to these broader issues is considered in this section.

The LC Joint Review Panel was struck to meet the EA requirements of the LC project under provincial and federal EA legislation and to assist government decision makers in determining whether and under what conditions the Project should be permitted to proceed. It is formally recognized in most EA legislation including CEAA that the purpose of EA is to ensure projects contribute to sustainable development. 46

Under the CEAA, the goal of contributing to sustainable development is partially met through the legal test that a project that is likely to cause significant adverse 
environmental effects can only proceeds if federal decision makers conclude that the impacts are justified in the circumstances. The test of "justified in the circumstances" allows federal decision makers to engage in a discussion of whether significant adverse effects are warranted because of the overall benefits of the project. As discussed in the CEAA literature, however, the federal EA process serves a broader purpose to inform decisions makers about the environmental implications of their decisions and to assist them in deciding whether to exercise their general discretion to approve or otherwise support the project. ${ }^{47}$ Provincial decision makers generally have even broader discretion to determine whether a project should proceed in light of the results of the EA process.

As discussed in some detail in the previous section, the LC panel was specifically mandated to consider the need and purpose of the project, the economic justification for the project, benefits and ways to enhance them, and alternatives to the project. These are all issues that go beyond the identification of significant adverse environmental effects. They collectively challenged the Panel to consider how to assist federal and provincial decision makers in making their project decisions in light of the environmental effects identified.

In case of the LC process, the panel report informs the provincial EA decision under section 67 of the Newfoundland \& Labrador Environmental Protection Act ${ }^{48}$ and the federal decision under section 37 of the Canadian Environmental Assessment Act. In both cases, the decision maker is required to consider whether the project should proceed and if so, under what conditions. In both cases, the report of the panel is the only source of information for decision makers identified in the legislation.

In short, in case of a joint review panel such as LC, both federal and provincial decision makers have to determine, in light of the adverse effects, benefits, risks and uncertainties identified in the panel report, whether the project should proceed. The LC panel report offers as the test for this decision whether the project is likely to make a net positive contribution to sustainability. ${ }^{49}$ This approach proposed by the LC panel is similar to the approach taken in other recent panel reports. ${ }^{50}$

To assist federal and provincial decision makers in their respective decisions, the panel started to consider early in its deliberations how to determine whether the project as proposed would contribute to sustainable development in affected communities, in Labrador, and in the province of NL. It eventually proposed a test for net positive contribution to sustainability and in the final report sought to demonstrate how such a test might be applied. ${ }^{51}$

Well before the hearings, the panel released for public comment draft criteria to determine whether the project would make a net positive contribution to sustainability. The panel furthermore scheduled a topic specific hearing on cross cutting issues during the regular hearing process, which included the topic of sustainable development. 
In line with the draft framework and after considering the comments received, the panel finalized its proposed criteria for a net positive contribution to sustainability and included them as an appendix to the report. ${ }^{52}$ At the heart of the Panel's approach was that the benefits, costs, risks and uncertainties of the project should be fairly distributed among affected communities, jurisdictions and generations, and that the project should result in net environmental, social and economic benefits..$^{53}$

The proposed sustainability framework consists of two main components. The first component is a set of general criteria to identify the range of impacts on sustainability the project is predicted to have. It challenges project proponents and decision makers to look for ways to ensure net environmental, social and economic benefits. Individually, benefits in any one of these areas do not have to be distributed equally, but collectively the framework is designed to ensure a fair distribution of benefits among affected communities and jurisdictions and between present and future generations. In short, the first component of the sustainability framework was designed to assist decision makers in identifying opportunities to avoid negative impacts, and to enhance positive contributions to sustainability. Under ideal circumstances, the application of these criteria results in a project that offers net positive contribution in all areas defined, requiring no trade-off decisions.

In recognition of the reality that this ideal will be rarely achieved, the second component of the framework sets out the panel's proposed approach to residual impacts. The principles in this part are intended to assist the decision makers in assessing the range of positive and negative social, economic and environmental impacts of the project to confirm whether the project can be expected to make a net positive contribution to sustainability and to ensure a fair distribution of impacts, benefits, risks and uncertainties. In short, the second component helps decision makers determine whether the impacts, benefits, risks and uncertainties are distributed fairly, and whether the trade-offs are defensible from a sustainability perspective.

So far, panels such as the LC panel have experimented with sustainability-based assessments without clear legislative or policy guidance. Considerable experience has been gained. Much of the experience so far has drawn on the sustainability literature, and the literature in turn has benefited from the early experimentation. There is, however, still a divergence of approaches, and the lack of law and policy clarity is limiting the effectiveness of the sustainability assessments carried out.

The lack of clarity in the terms of reference developed for panels is raising doubts in some participants about the appropriateness of sustainability assessments. Furthermore, few participants are familiar with sustainability assessments. In the absence of clear guidance on the role of sustainability assessments in project EA and guidance on how they are to be conducted, many participants in the LC process did not engage on this issue and instead focused on what they knew, the more traditional discussion on significant adverse environmental effects. This, in turn, 
contributed to significant information gaps, which made the application of the sustainability framework more difficult for the LC panel.

The challenges with these early efforts to incorporate sustainability assessments into project EAs suggest that it may be time to formally recognize the contribution this approach makes to the effectiveness of project EA, and to offer specific guidance to all participants. Only then can we expect proponents and intervenors to provide the information needed and to more fully engage in this part of the project EA process. This, in turn, will enable Panels to more fully utilize this tool to assist government decision makers in making decisions on energy project that move us toward a sustainable energy future.

\section{Conclusion}

It is clear from the LC experience that project EAs can and do have an important role to play to facilitate a transition to a sustainable energy future. There are a number of general improvements to the current panel review process that would enhance the ability of project EAs to contribute to this effort. In addition, there are two aspects of project EA as applied in the LC panel review process that should be enhanced, the approach to alternatives, and the formal incorporation of an assessment of the project's net contribution to sustainability into the EA process.

With these modest enhancements, project based panel reviews have the potential to make a substantial contribution to a transition to a sustainable energy future. It is clear, however, that the project level alone is insufficient. The absence of a higher tier context clearly hindered the ability of the LC review to properly place the LC project in a broader sustainable energy context. Not enough was known about how the power from the LC project would be integrated into various electricity markets, and what role electricity will play in meeting future energy needs in those markets.

This broader context is critical, and would be more effectively developed through national or regional sustainable energy policies that include consideration of production, distribution, export, conservation and demand management, and an economic strategy that is integrated with a sustainable energy strategy.

Possible tools for facilitating the development of such broader policies include regional and strategic environmental assessments on sustainable energy. Such SEAs and REAs could be carried out in a comprehensive manner at a national or regional level, or they could be carried out for specific energy sources, and issues such as transmission, and demand and supply management. 
${ }^{1}$ Canadian Environmental Assessment Act (CEAA), S.C. 1992, c. 37.

2 For panel reports on energy projects carried out under CEAA, see CEAA website at http://www.ceaa.gc.ca/010/type5index-eng.cfm.

${ }^{3}$ Robert Gibson et al, "Strengthening Strategic Environmental Assessment in Canada: An Evaluation of Three Basic Options" (2010) 20 J. Env. L. \& Prac. 175

4 CEAA, section 16

5 CEAA, section 37

${ }^{6}$ For information about the Lower Churchill EA process including all documents filed, see Lower Churchill Hydroelectric Generation Project reference number 07-05-26178, CEAA registry at http://www.ceaa.gc.ca/050/index-eng.cfm.

7 The author was a member of the Lower Churchill Joint Review Panel. The views expressed here are the authors alone and do not necessarily reflect the views of the other panel members.

8 See Lower Churchill Hydroelectric Generation Project: Report of the Joint Review Panel (August 23, 2011), available at http://www.ceaa.gc.ca/050/index-eng.cfm.

${ }^{9}$ See LC Panel Report

10 See Labrador-Island Transmission Link Project Newfoundland and Labrador, reference number 10-03-51746 on CEAA Registry at http://www.ceaa.gc.ca/050/index-eng.cfm. 11 Maritime Link Transmission Project, reference number 12-01-65713, on CEAA Registry at http://www.ceaa.gc.ca/050/index-eng.cfm.

12 See Part II of Terms of Reference, LC Panel Report, Appendix 2

${ }^{13}$ See Part II of Terms of Reference, LC Panel Report, Appendix 2

14 See CEAA Registry at http://www.ceaa.gc.ca/050/index-eng.cfm for the Environmental Impact Statement (EIS) filed by the proponent

15 See CEAA Registry for information requests filed by the Panel and responses submitted by the proponent.

16 ibid.

17 See Panel Report at 1-7 for an overview of the process

18 Government of Canada Response to the Report of the Joint Federal-Provincial Review Panel for Nalcor's Lower Churchill Generation Project in Newfoundland and Labrador (March 15, 2012) available at http://www.ceaa-acee.gc.ca/050/document-

eng.cfm?document=54772. Government of Newfoundland and Labrador's Response to the Report of the Joint Review Panel for Nalcor Energy's Lower Churchill Hydroelectric Generation Project (March 15, 2012) available at http://www.env.gov.nl.ca/env/Response_to_Panel_Report.pdf.

${ }^{19}$ See Panel Report at 1-7 for an overview of the process

20 See Correspondence to Aboriginal groups from the Federal Government regarding the Federal Aboriginal Consultation Framework, CEAR \# 444. This consultation framework was introduced without involvement of the panel.

${ }^{21}$ See Panel Report, Ch. 9, 10

22 See Panel Report, Ch.9

${ }^{23}$ See Panel Report, including Appendix 5, 6 and CEAA Registry at http://www.ceaa.gc.ca/050/index-eng.cfm for intervenor submissions

${ }^{24}$ See Panel Report. Each chapter contains a section that summarizes the views of participants.

25 See Panel Report, Ch. 17

${ }^{26}$ See Panel Report, Ch. 17 
27 See, for example, 2007 panel report regarding the Whites Point Quarry in Digby Neck, NS, or the 1997 panel report involving the Voisey's Bay Nickel Mine in Labrador. For further information of these panel reviews, see CEAA website at http://www.ceaa.gc.ca/010/type5index-eng.cfm.

${ }^{28}$ One particularly contentious issue in this regard was the purpose of the project. Section 2 of the EIS Guidelines directed the proponent to discuss the purpose from its own perspective. However, the terms of reference were not limited in the same manner. The proponent defined the purpose of the project among others to be the realization of the full hydro potential of the LC river, in line with the provincial energy strategy. Not surprisingly, many intervenors had different view on an appropriate purpose of the project.

${ }^{29}$ One critical area in this regard, discussed below, is the need and purpose of the project, and the effect of need and purpose on the consideration of alternatives to the project.

30 See section 3 of EIS Guidelines for a list of key terrestrial indicator species. The Guidelines are available on the CEAA registry at http://www.ceaa.gc.ca/050/index-eng.cfm. 31 The most common criticism of the LC panel process was the failure of the Panel to hold community hearings in communities who felt they had a stake in the process. In the time available, it was practically impossible to accommodate these requests, resulting in an unnecessary loss of credibility of the process for the sake of a couple of weeks in a multi year process.

32 The sufficiency determination was made public on January 24,2011 . The relevant document is missing from the CEAA registry, but is on file with the author. 33 Some of these challenges are avoidable if the panel is involved in developing the EIS guidelines, and is permitted to hold scoping hearings to engage intervenors in key issues. Nevertheless, some knowledge gaps at the conclusion of an EA process, no matter how thorough and well designed, are inevitable. In dealing with such gaps, panels need to give careful thought to the relationship between information gaps, uncertainty, significance findings, monitoring, follow-up and adaptive management. For example, if the missing information could affect the likelihood or significance of an environmental effect, how should the absence of the information affect the panel's findings? Does it make a significance finding less or more likely? When should knowledge gaps result in a significance finding using a precautionary approach? When would it be enough to propose monitoring, follow-up and adaptive management to address the gap? Does it matter whether the information was previously requested by the Panel or the issue arises out of new information brought up for the first time at the hearing?

34 It is worthwhile to reflect on the role of the secretariat in a panel review process and the practical difficulties involved in living up to the principle that Panels should make all procedural and substantive decisions, when Panel members are often not process or legal experts, and in some cases secretariat analysts are relied upon for substantive advice. The result is that secretariat members can at times be very influential in determining what the panel does and does not do.

35 An interesting general observation from the perspective of a panel member is that a number of government departments were quite critical of specific aspects of the EIS, but did not persist when the proponent did not address their concerns. In some cases, even upon being questioned about this at the hearings, departments would step back from the strong criticisms they had expressed at the EIS review stage.

36 There were in fact two amendments to the Terms of Reference. See Panel Report, Appendix 2.

${ }^{37}$ At the same time, it was a challenge for the panel to encourage the proponent to view the process as a mutual learning opportunity, and not an adversarial process. 
38 The Panel did not receive enough information on potential alternatives to complete the analysis. Instead, the Panel recommended that an independent alternatives assessment be commissioned. This decision is currently subject to judicial review. See Judicial Review Application filed on behalf of Grand River Keepers, Sierra Club of Canada and Nunatukavut Community Council Inc. (December 20, 2011), available at http://www.ecojustice.ca/media-centre/media-release-files/notice-of-application-lowerchurchill-generation-project/at_download/file.

39 The absence of a national sustainable energy strategy certainly hindered the work of the panel. Of course, there was a provincial energy strategy in place, however, it advocated for the full development of the hydro potential without articulating limits or alternatives to this goal, without articulating how decisions should be made about individual projects, and without considering the regional context.

40 This conclusion was base on a separation between the EIS Guidelines, which ask to proponent to consider need, purpose, and alternatives from its perspective, and the Panel's Terms of Reference, which did not contain these restrictions.

41 This conclusion was based on the clear indication from the proponent that power from the Gull Island facility was destined for export. Only Muskrat Falls power would be available to meet demand in NL and the rest of Atlantic Canada.

42 The Public Utilities Board of Newfoundland and Labrador reported similar challenges getting information from the proponent on the economics of the project. See Newfoundland \& Labrador Board Of Commissioners Of Public Utilities Review Of Two Generation Expansion Options For The Least-Cost Supply Of Power To Island Interconnected Customers For The Period 2011 - 2067 (March 30, 2012) available at http://www.gov.nl.ca/lowerchurchillproject/muskrat_falls_pub_final_report.pdf.

43 The panel was unable to independently confirm these conclusions based on the limited information provided. An independent assessment subsequently carried out by Manitoba Hydro International on behalf of the PUB in Newfoundland and Labrador did not consider a broad range of alternatives in considering the economic viability of Muskrat Falls. See Manitoba Hydro International Report (January, 2012) available at http://www.pub.nf.ca/applications/MuskratFalls2011/index.htm. 44 Included in this list of issues is the ongoing battle with Hydro Quebec over transmission access through Quebec to markets in Ontario and the US.

45 Interestingly, even the province of Nova Scotia and its power utility chose not to participate in the hearings. As a result, there was limited information available on the impact of power from Muskrat Falls on energy prices, energy security or GHG emissions in Nova Scotia.

${ }^{46}$ See CEAA, Preamble, s. 4. For a more detailed analysis of the role of sustainable development in CEAA, see M. Doelle The Federal Environmental Assessment Process: A Guide and Critique (Markham, Ont.: LexisNexis Butterworths, 2008) at 186 - 198

47 ibid.

${ }^{48}$ Environmental Protection Act, S.N.L. 2002, c. E-14.2

${ }^{49}$ See Lower Churchill Panel Report, ch. 17.

50 See, for example, Panel Reports regarding the Voisey's Bay Mine and Mill Project, the Kemess North Gold-Copper Mine, the Whites Point Quarry and Marine Terminal Project, and the Mackenzie Gas Project. For copies of these various panel reports, see CEAA website at http://www.ceaa.gc.ca/010/type5index-eng.cfm.

51 See Lower Churchill Panel Report, ch. 17.

52 See Lower Churchill Panel Report, Appendix 8 
53 The concept of net contribution to sustainability was first explored in detail in Gibson, R.B., et al, Sustainability Assessment: Criteria, Processes and Applications. (London:

Earthscan, 2005). 